Article

\title{
Production of D-Lactic Acid by the Fermentation of Orange Peel Waste Hydrolysate by Lactic Acid Bacteria
}

\author{
Daniel Bustamante ${ }^{1,2} \mathbb{D}$, Marta Tortajada ${ }^{2}$, Daniel Ramón ${ }^{2}$ and Antonia Rojas ${ }^{2, * \mathbb{D}}$ \\ 1 Current address: National Renewable Energy Centre (CENER), Av. Ciudad de la Innovación, 7, \\ 31621 Sarriguren, Spain; dbustamante@cener.com \\ 2 ADM-BIOPOLIS, Parc Científic Universitat de València, C/Catedrático Agustín Escardino, 9, 46980 Paterna, \\ Spain; marta.tortajada@adm.com (M.T.); daniel.ramonvidal@adm.com (D.R.) \\ * Correspondence: antonia.rojas@adm.com
}

Received: 31 October 2019; Accepted: 16 December 2019; Published: 18 December 2019

\begin{abstract}
Lactic acid is one the most interesting monomer candidates to replace some petroleumbased monomers. The application of conventional poly-lactic acid (PLA) is limited due to insufficient thermal properties. This limitation can be overcome by blending poly-D and poly-L-lactic acid. The main problem is the limited knowledge of D-lactic acid (D-LA) production. Efficient biochemical processes are being developed in order to synthesize D-LA from orange peel waste (OPW). OPW is an interesting renewable raw material for biorefinery processes of biocatalytic, catalytic or thermal nature owing to its low lignin and ash content. Bioprocessing of the pretreated OPW is carried out by enzymatic hydrolysis and fermentation of the released sugars to produce D-LA. Several strains of the species Lactobacillus delbrueckii ssp. bulgaricus have been evaluated for the production of D-LA from OPW hydrolysate using Lactobacillus delbrueckii ssp. delbrueckii CECT 286 as a reference strain since its performance in this kind of substrate have been widely reported in previous studies. Preliminary results show that Lactobacillus delbrueckii ssp. bulgaricus CECT 5037 had the best performance with a yield of $84 \% w / w$ for D-LA production and up to $95 \%$ (e.e.).
\end{abstract}

Keywords: added value product; D-lactic acid; LAB strains; food waste; orange peel waste

\section{Introduction}

Lactic acid is an important chemical and has attracted a great attention due its widespread applications in the food, pharmaceutical, cosmetic, and textile industries. Polylactic acid (PLA) is a biodegradable polymer with great potential in replacing petrochemical polymers and therefore, L-and D-lactic acids are prominent monomers of the bioplastic industry [1]. The morphological, mechanical and thermal properties of the polymer are determined by the presence of different amounts of L- and D-lactic acid monomers or oligomers [2-6]. Microbial production of optically pure lactic acid has extensively been studied because chemically synthesized lactic acid is a racemic mixture [7]. In fact, the optimization of operation conditions is very effective to achieve high selectivity to the isomer of interest [8]. Although the L-isomer has been studied in detail, information on biosynthesis of D-lactic acid (D-LA) is still limited [5,9].

PLA market demand accounts for $11.4 \%$ of total bioplastic production worldwide, approximately $18 \times 10^{4}$ metric tons per year and the PLA demand is estimated to grow by $28 \%$ per year until 2025 . However, production costs of PLA are still high, mainly due to expensive fermentation media components. To overcome this problem, several residues have been employed as raw material [3,5,7,10-12]. Production of D-LA from liquid pineapple wastes [13], date juice [14], corn stover [15], hardwood pulp hydrolysate [16] and brown rice [17] has been studied. In this sense, the valorization of food waste to 
useful products such as D-LA is a good alternative $[1,18,19]$. In particular, orange peel and pulp waste (OPW) can be used to produce D-LA after adequate pre-treatment processes [20-22].

Orange waste is the most abundant citrus waste with up to 50 million metric tons of oranges consumed every year [23]. This huge amount of waste accounts for $45 \%-60 \%$ of the total fruit weight, and therefore, a lot of potential applications have been studied for their valorization to date [24]. The main application of this residue is as an ingredient for cattle feed or as pelletized dry solid fuel, but its processing results in highly polluted wastewater [25]. The use of citrus waste to produce compounds of high added value, essential oils, fertilizer, pectin, industrial enzymes, ethanol and absorbents has recently been described [21,23-28]. In addition, orange waste present low levels of lignin and a large amount of sugars [27], which make it an ideal substrate for fermentation processes after the implementation of the required pre-treatment and enzymatic hydrolysis stages.

Lactic acid is produced in high amounts by lactic acid bacteria (LAB) which can do so in a homofermentative way employing the Embden-Meyerhof pathway where lactic acid is the only acid produced, or by the heterofermentative way following the phosphogluconate and phosphoketolase pathway where lactic acid is one of the products and yields of $0.5 \mathrm{~g} \mathrm{~g}^{-1}$ of hexose. LABs produce either one or the two forms of lactate $[4,11,29,30]$. The species Lactobacillus delbrueckii ssp. delbrueckii has been reported as a homofermentative producer of D-LA using several agro-industrial residues [9]. This bacterium yields $90 \%$ D-LA from sugarcane molasses, 95\% D-LA from sugarcane juice, $88 \%$ D-LA from sugar beet juice [31] and 88\% D-LA from orange peel waste (OPW) [32]. Moreover, the species Lactobacillus delbrueckii subsp. bulgaricus has been used in the dairy industry to transform milk into yogurt and some strains are able to produce highly pure D-LA [33]. Therefore, lactose and whey have been widely studied as raw materials for lactic acid production [34-36], even cloning the D-lactate dehydrogenase gene in Escherichia coli [37]. Other studies included wheat flour, molasses, sorghum and lignocellulosic hydrolysates as feedstocks for the production of lactic acid by Lactobacillus delbrueckii subsp. bulgaricus, especially for L-LA isomer production [11,38]. This fact means that some strains of Lactobacillus delbrueckii subsp. bulgaricus could be potential candidates for D-LA production from sustainable feedstocks.

The aim of this work was to find LAB strains capable of producing D-LA with high yield and optical purity from OPW as raw material to contribute in the development of biowaste-refineries. For this purpose, several Lactobacillus delbrueckii ssp. bulgaricus strains were evaluated in comparison to the reference strain Lactobacillus delbrueckii ssp. delbrueckii CECT 286 which has been reported as a high yield producer of D-LA from biowaste and OPW hydrolysate in particular.

\section{Materials and Methods}

\subsection{Bacterial Strains, Media and Growth Conditions}

The bacterial strains employed in this study are listed in Table 1 and Lactobacillus delbrueckii ssp. delbrueckii CECT 286 was used as reference strain. The selected strains were purchased from the Spanish Type Culture Collection (CECT). After being received they were recovered in MRS medium and stored in $20 \%$ glycerol at $-80{ }^{\circ} \mathrm{C}$ for long-term preservation. Precultures were prepared in tubes containing MRS medium with a small headspace and incubated overnight at $37^{\circ} \mathrm{C}$ and static micro-aerobic conditions.

Table 1. Lactic acid bateria (LAB) strains selected for D-lactic acid production screening.

\begin{tabular}{cc}
\hline \multicolumn{1}{c}{ Microorganism } & Strain Code \\
\hline L. delbrueckii ssp. bulgaricus & CECT 4005 \\
L. delbrueckii ssp. bulgaricus & CECT 4006 \\
L. delbrueckii ssp. bulgaricus & CECT 5035 \\
L. delbrueckii ssp. bulgaricus & CECT 5036 \\
L. delbrueckii ssp. bulgaricus & CECT 5037 \\
L. delbrueckii ssp. bulgaricus & CECT 5038 \\
\hline
\end{tabular}


Screening of $\mathrm{LAB}$ strains was performed in $15 \mathrm{~mL}$ tubes at $37^{\circ} \mathrm{C}$ and using a medium with sugars resembling OPW hydrolysate as follows: MRS broth plus glucose $30 \mathrm{~g} \mathrm{~L}^{-1}$, fructose $20 \mathrm{~g} \mathrm{~L}^{-1}$, galactose $5 \mathrm{~g} \mathrm{~L}^{-1}$ and arabinose $6 \mathrm{~g} \mathrm{~L}^{-1}$. Cultures were inoculated in duplicate with $5 \% \mathrm{v} / \mathrm{v}$ of preculture and were incubated in orbital shaker at $200 \mathrm{rpm}$. Aerobic and micro-aerobic conditions were tested at $\mathrm{pH} 6.2$ for $40 \mathrm{~h}$.

\subsection{OPW Hyrolysate Tolerance Assays}

Tolerance assays were performed in triplicate using selected strains and preparing a multi-well plate with $200 \mu \mathrm{L}$ of MRS with OPW hydrolysate diluted at 50\%, 85\% and 100\% $v / v$ as culture medium for each condition. Precultures were prepared in MRS and inoculated at $10 \%$ of total volume. A microplate incubator spectrophotometer was used with temperature set at $37^{\circ} \mathrm{C}$ for $45 \mathrm{~h}$. The plate was shaken every hour for 5 seconds before each $\mathrm{OD}_{600}$ measurement to obtain the growth curves of the strains.

\subsection{Fermentation Assays}

Strains were cultured in $50 \mathrm{~mL}$ tubes containing MRS with 85\% v/v OPW hydrolysate at pH 6.2, $37^{\circ} \mathrm{C}$ and $45^{\circ} \mathrm{C}$ in micro-aerobic conditions. An additional assay was done by adjusting $\mathrm{pH}$ at 5.8 each $24 \mathrm{~h}$ with $\mathrm{NaOH} 5 \mathrm{M}$. All runs started by inoculating $15 \% \mathrm{v} / \mathrm{v}$ of preculture and then incubated in an orbital shaker at $200 \mathrm{rpm}$ for $120 \mathrm{~h}$.

The experiments in the bioreactor setup were performed in $1.5 \mathrm{~L}$ Applikon ${ }^{\circledR}$ in batch mode with OPW hydrolysate at $85 \% \mathrm{v} / \mathrm{v}$ with MRS and $5 \mathrm{~g} \mathrm{~L}^{-1}$ meat extract as additional nitrogen source. The OPW hydrolysate was sterilized using sterile glass fiber and cellulose acetate membrane filters with $0.2 \mu \mathrm{m}$ of pore size, and then added to the bioreactor. Before the inoculum addition, the anaerobic atmosphere was obtained by stripping the oxygen off with a nitrogen stream. The experimental conditions were set up at $37^{\circ} \mathrm{C}, 200 \mathrm{rpm}$, and $\mathrm{pH}$ of 5.8, adding $\mathrm{NaOH} 5 \mathrm{M}$ or $\mathrm{HCl} 2 \mathrm{M}$ for $\mathrm{pH}$ control during fermentation.

\subsection{OPW Pretreatments}

The substrate used in this study was OPW obtained from juice elaboration. These residues were blade-milled to a final particle diameter of around $5 \mathrm{~mm}$ and then, samples were subsequently stored in a freezer at $-20^{\circ} \mathrm{C}$ until use. The characterization of the raw material was performed according to the NREL procedures for determination of structural carbohydrates and free sugars, in addition to extractives [39-41], while moisture was assessed by using an infrared drying balance at temperatures between 70 and $90^{\circ} \mathrm{C}$ until constant weight. The results obtained by applying the NREL methodology are compiled in Table 2. For D-LA production assays, OPW was milled down to 1-2 mm particle size and hydrolysis was carried out at $10 \% \mathrm{w} / \mathrm{w}$ of dry solid, $50{ }^{\circ} \mathrm{C}, 300 \mathrm{rpm}$ and initial pH of 5.2 using enzyme cocktails with cellulases, $\beta$-glucosidase, xylanase, $\beta$-xylosidase, pectinase, and auxiliary activities (Celluclast 1.5 1, Novozym 188, Pectinex Ultra SP-L gifted by Novozymes) as described by de la Torre and colleagues [22].

Table 2. OPW composition analysis according to NREL protocols.

\begin{tabular}{cc}
\hline Component & \% Dry Weight $(w / w)$ \\
\hline Total solids & $19.2 \pm 0.5$ \\
Ash & $3.9 \pm 0.2$ \\
Fats & n.d. \\
Water & $37.5 \pm 0.4$ \\
extractives & \\
Free sugars & $36.4 \pm 0.6$ \\
Glucan & $19.1 \pm 0.1$ \\
Hemicellulose & $14.8 \pm 0.2$ \\
Lignin & $6.2 \pm 0.5$ \\
Pectin & $17.9 \pm 1.5$ \\
\hline
\end{tabular}




\subsection{Analytical Procedures}

The content of sugars and organic acids was determined by HPLC liquid chromatography (2695 HPLC with a refractive Index Detector 2414; Waters, Cerdanyola del Vallés, Spain) using a Rezex ROA Organic acid column, with $\mathrm{H}_{2} \mathrm{SO}_{4}$ at $2.5 \mathrm{mM}$ and $0.5 \mathrm{~mL} \mathrm{~min}^{-1}$ flow. The optical purity of D-LA was determined by HPLC (Agilent Technologies 1100 Series, Waldbronn, Germany) using a DAD detector, a Chirex 3126 (D)-penicillamine $(250 \times 4.6$; Phenomenex $)$ column working at room temperature, and a $\mathrm{CuSO}_{4} 1 \mathrm{mM}$ solution as mobile phase flowing at $1.2 \mathrm{~mL} \mathrm{~min}^{-1}$.

\section{Results and Discussion}

\subsection{Screening of LAB Strains for D-LA Production}

Lactic acid production was tested in $15 \mathrm{~mL}$ tubes containing $3 \mathrm{~mL}$ of culture resembling OPW hydrolysate for aerobic conditions and $14 \mathrm{~mL}$ of culture for micro-aerobic conditions to compare the behavior of the different LAB strains. Results are shown in Figure 1. Lactobacillus delbrueckii ssp. bulgaricus CECT 4005 and CECT 5038 did not produce a significant amount of lactic acid while L. delbrueckii ssp. bulgaricus CECT 5036 produced up to $14 \mathrm{~g} \mathrm{~L}^{-1}$ of lactic acid racemic mixture in aerobic and micro-aerobic conditions. Furthermore, three strains, L. delbrueckii ssp. bulgaricus CECT 4006, CECT 5035 and CECT 5037 transformed sugars into lactic acid in micro-aerobic condition with D-LA enantiomeric excess in the same way as L. delbrueckii ssp. delbrueckii CECT 286. Those strains produced around $15 \mathrm{~g} \mathrm{~L}^{-1}$ of lactic acid with around $75 \%$ (e.e.) of D-LA while L. delbrueckii ssp. delbrueckii CECT 286 reached $92 \%$ (e.e.) of D-LA. Therefore, those three strains were selected to study D-LA production from OPW hydrolysate in micro-aerobic conditions.
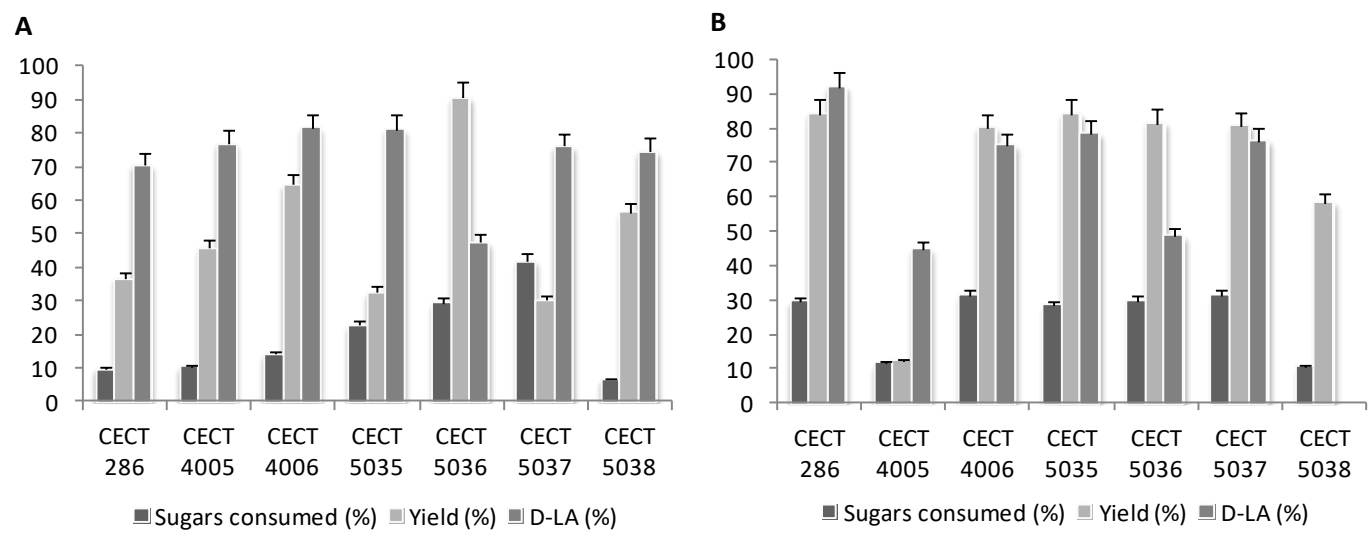

Figure 1. D-LA production in $15 \mathrm{~mL}$ tubes with MRS medium containing sugars resembling OPW hydrolysate using LAB strains selected for screening. A. Aerobic conditions. B. Micro-aerobic conditions.

Previous reports showed that lactose rather than glucose markedly increases the growth rate of L. delbrueckii ssp. bulgaricus strains [33,34]. Therefore, transport systems of sugars other than lactose are likely to vary among these strains and hence, some strains, such as L. delbrueckii ssp. bulgaricus CECT 4005 and CECT 5038, appear to have difficulties to assimilate the sugars tested in this work. Moreover, strains such as L. delbrueckii ssp. bulgaricus CECT 5035 and CECT 5037 show low yield in assays at aerobic conditions in the same way as L. delbrueckii ssp. delbrueckii CECT 286. It is known that during growth, toxic oxygen derivatives are produced for LAB strains in aerobic conditions, but the enzymes required to eliminate them seem not to be expressed in some L. delbrueckii ssp. bulgaricus strains [42]. Reducing agents may provide protection against toxic products, particularly if growth conditions are not strictly anaerobic. However, with exception of L. delbrueckii ssp. bulgaricus CECT 5036, the other strains showed higher selectivity to D-LA than L. delbrueckii ssp. delbrueckii CECT 286 in aerobic conditions and as mentioned above, L. delbrueckii ssp. bulgaricus CECT 5036 have similar results at 
aerobic and micro-anaerobic conditions but produced racemic mixture in both cases. L. delbrueckii ssp. bulgaricus CECT 4005 appears to prefer aerobic conditions but yields are still low.

\subsection{Use of OPW Hydrolysate for D-LA Production by Selected Strains}

The OPW hydrolysates were prepared following the methodology described in Section 2.4. and developed by de la Torre and colleagues [22] obtaining a glucose yield around $60 \% w / w$ which corresponds to around $30 \mathrm{~g} \mathrm{~L}^{-1}$, and obtaining a total sugar concentration above $50 \mathrm{~g} \mathrm{~L}^{-1}$. Therefore, OPW is a good source of several monosaccharides but also have essential oils rich in limonene and containing terpenes and phenolics with some antimicrobial activity [21]. The tolerance of the strains to the substrate was tested with different concentrations of OPW hydrolysate ranging from $50 \%$ to $100 \% v / v$ diluted with MRS broth. Growth monitoring was performed in a micro-plate incubator for $48 \mathrm{~h}$ (Figure 2). Microorganisms grew up well at 50\% $v / v$ hydrolysate content, but the strain L. delbrueckii ssp. delbrueckii CECT 286 tolerated the hydrolysate and was able to grow even when hydrolysate content was $100 \%$ v/v. Lactobacillus delbrueckii ssp. bulgaricus CECT 4006 appears to be more sensitive to OPW hydrolysate while L. delbrueckii ssp. bulgaricus CECT 5037 was able to grow up at any OPW concentration; however, the higher the hydrolysate concentration, the higher the lag phase and the lower the growth. Differences lied on the performance of the strains, which is slightly lower when using OPW hydrolysates, probably due to the presence of essential oil components, either terpenes or phenolics. However, Lactobacilli are able to withstand relatively high concentrations of citrus extracts [43].
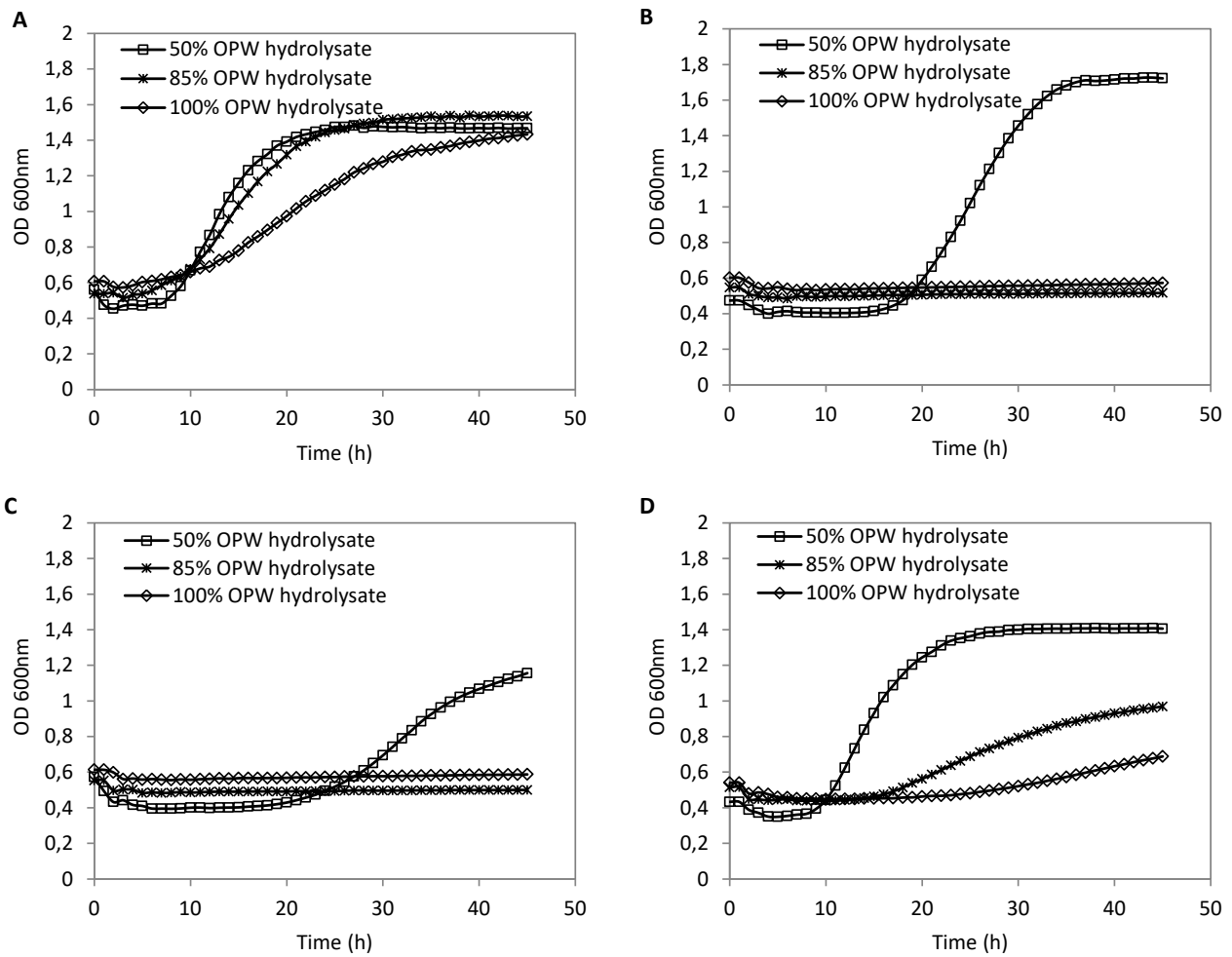

Figure 2. Growth curves for tolerance assays to OPW hydrolysate in microplates and microarebic conditions. (A) Lactobacillus delbrueckii ssp. delbreckii CECT 286. (B) Lactobacillus delbrueckii ssp. bulgaricus CECT 4006. (C) Lactobacillus delbrueckii ssp. bulgaricus CECT 5035. (D) Lactobacillus delbrueckii ssp. bulgaricus CECT 5037. The results were obtained as the average of three replicates and standard deviation was lower than $0.5 \%$.

Concerning the nutritional requirements, previous studies showed that niacin, calcium pantothenate, riboflavin, and vitamin B12 were essential for the growth of L. delbrueckii ssp. bulgaricus, and that folic acid, pyridoxal, and $\mathrm{CaCl}_{2}$ were important for efficient growth [44,45]. There could be discrepancies due to 
differences in medium composition or to strain-specific requirements as in the case of L. delbrueckii ssp. bulgaricus CECT 5037, which not only seems to tolerate hydrolysate, but also seems to grow with less strict nutritional requirements. Although L. delbrueckii ssp. delbueckii CECT 286 and L. delbrueckii ssp. bulgaricus CECT 5037 have shown highest robustness cultured in OPW hydrolysate, the next assays were performed using the four selected strains and inoculating the cells recovered from $15 \% v / v$ of preculture with respect to the volume of culture at 85\% v/v OPW hydrolysate diluted with MRS medium and micro-aerobic conditions. The inoculum amount was increased to compare the performance of the selected strains with the maximum concentration of OPW hydrolysate during the preliminary fermentation trials.

The optimal growth temperature for Lactobacilli ranges from 30 to $40{ }^{\circ} \mathrm{C}$, although some thermophilic strains grow well and have highly activated metabolism at temperatures around $45^{\circ} \mathrm{C}$ [35]. The four Lactobacillus strains selected were cultured at $37{ }^{\circ} \mathrm{C}$ and $45^{\circ} \mathrm{C}$ during $120 \mathrm{~h}$ to test their activity at conditions as close as possible to those of hydrolysis stage and therefore, to evaluate if the hydrolysis and fermentation stages could be done simultaneously (SSF) as a preliminary result for the future optimization and scale-up of the process. In general, the SSF process offers better yields because it avoids product inhibition and results in higher productivity [10]. Aghababaie and colleagues [36] reported that optimum temperature and $\mathrm{pH}$ for growth and lactate production from whey for L. delbrueckii ssp. bulgaricus were $44^{\circ} \mathrm{C}$ and 5.7, respectively. However, the results in Figure 3 show that the strains selected in this study produced D-LA up to $90 \%$ (e.e.) in all cases, but the performance of the strains was still better at $37^{\circ} \mathrm{C}$ using OPW hydrolysates.

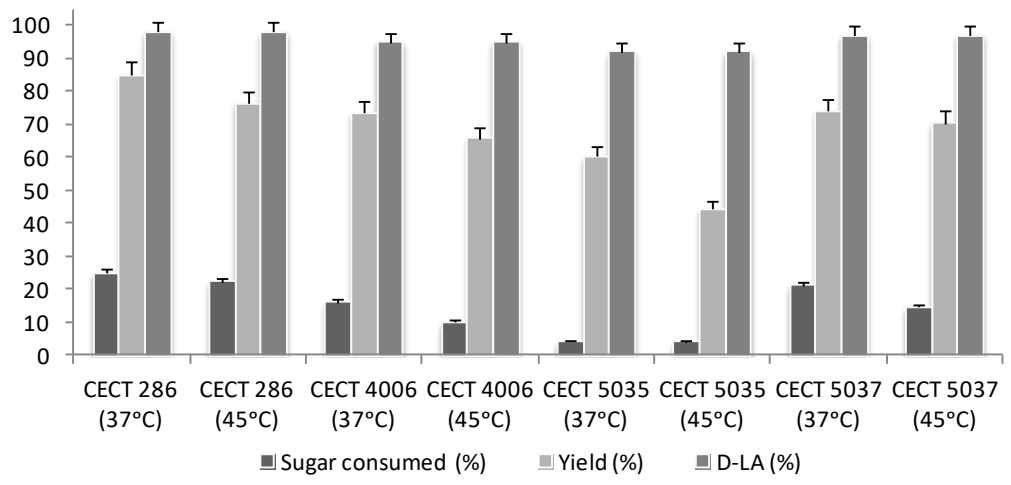

Figure 3. D-LA production results of three L. delbrueckii ssp. bulgaricus selected in front of L. delbrueckii ssp. delbrueckii CECT 286 using OPW hydrolysate at $85 \%$ v $v$ and incubated at $37{ }^{\circ} \mathrm{C}$ and $45^{\circ} \mathrm{C}$ to compare strains performance at different temperatures.

Similarly to temperature, the effect of $\mathrm{pH}$ change on growth characteristics varied between different species of LAB and in most cases, a decrease of lactate production with a decrease of $\mathrm{pH}$ were observed [35]. Therefore, the strains were cultured in $85 \%$ v/v OPW hydrolysate and $\mathrm{pH}$ was adjusted to 5.8 each $24 \mathrm{~h}$ during fermentation to test their capacity of production with $\mathrm{pH}$ regulation. Cultures were incubated at $37^{\circ} \mathrm{C}$ and micro-aerobiosis for $120 \mathrm{~h}$. The results show that sugar consumption and yields were higher when $\mathrm{pH}$ was adjusted, and D-LA up to 95\% (e.e.) was produced (Figure 4). L. delbrueckii ssp. bulgaricus CECT 5037 showed the best results in comparison to the other L. delbrueckii ssp. bulgaricus strains and its performance was comparable to L. delbrueckii ssp. delbrueckii CECT 286 strain using OPW hydrolysate, whose productivities were between 0.23 and $0.29 \mathrm{~g} \mathrm{~L}^{-1} \mathrm{~h}^{-1}$, respectively. Due to the homofermentation of L. delbrueckii ssp. delbrueckii and L. delbrueckii ssp. bulgaricus [9,11], only lactic acid could be produced. Nevertheless, a small increase in ethanol concentration onwards of $48 \mathrm{~h}$ of fermentation was observed during $\mathrm{pH}$ regulation trials. The explanation for this fact, according to the literature $[38,46]$, is that some homofermenters, when grown in limited sugar environment or in the presence of different sugars, can lead to other end products. The main difference is in pyruvate metabolism, but the homofermentation pathway is still used. Additionally, the accumulation of ethanol 
in the medium (2-3 $\left.\mathrm{g} \mathrm{L}^{-1}\right)$ was by far very low to change significantly the generation of the target product. Thus, D-LA continues to be the major fermentation product, and the metabolism of the strains can be considered homofermentative.

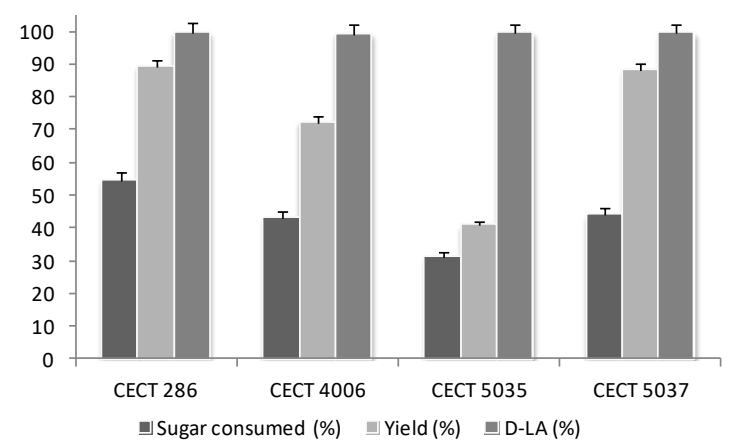

Figure 4. D-LA production results of three L. delbrueckii ssp. bulgaricus selected in front of L. delbrueckii ssp. delbrueckii CECT 286 using OPW hydrolysate at 85\% v/v and adjusting $\mathrm{pH}$ at 5.8 each $24 \mathrm{~h}$ to evaluate strains performance with $\mathrm{pH}$ regulation. The results of standard deviation for the strains with respect to CECT 286 strain are: $\mathrm{SD}_{\text {CECT } 4006}=12.02 ; \mathrm{SD}_{\text {CECT5035 }}=34.22 ; \mathrm{SD}_{\mathrm{CECT} 5037}=0.69$.

\subsection{D-LA Production by L. delbrueckii ssp. delbrueckii CECT 286 vs. L. delbrueckii ssp. bulgaricus CECT 5037}

Preliminary scale-up assays were performed in 1.5 liter bioreactor by controlling $\mathrm{pH}$ at 5.8 in batch mode. Previous results showed that the performance of the strains was better under micro-aerobic conditions, so the bioreactor tests were performed under anaerobic conditions using a nitrogen stream. Cells from 15\% v/v MRS preculture were inoculated in 85\% v/v OPW hydrolysate with MRS and supplemented with $5 \mathrm{~g} \mathrm{~L}^{-1}$ of meat extract. According to literature, the more supplemented the medium, the higher the value of final biomass and the higher the productivity of the lactic acid attainable [45,47]. Previous work showed the importance of meat extract and yeast extract in the production of D-LA, probably not due to the total amount of nitrogen but to the growth factors and vitamins contained in these extracts [32]. Fermentation was finished at $72 \mathrm{~h}$ (Figure 5), L. delbrueckii ssp. delbrueckii CECT 286 produced $45 \mathrm{~g} \mathrm{~L}^{-1}$ of lactic acid (99.5\% D-LA (e.e.)) with a yield of $86 \%$ w/w while L. delbrueckii ssp. bulgaricus CECT 5037 produced $39 \mathrm{~g} \mathrm{~L}^{-1}$ of lactic acid (99.3\% D-LA (e.e.)) with a yield of $84 \% w / w$.
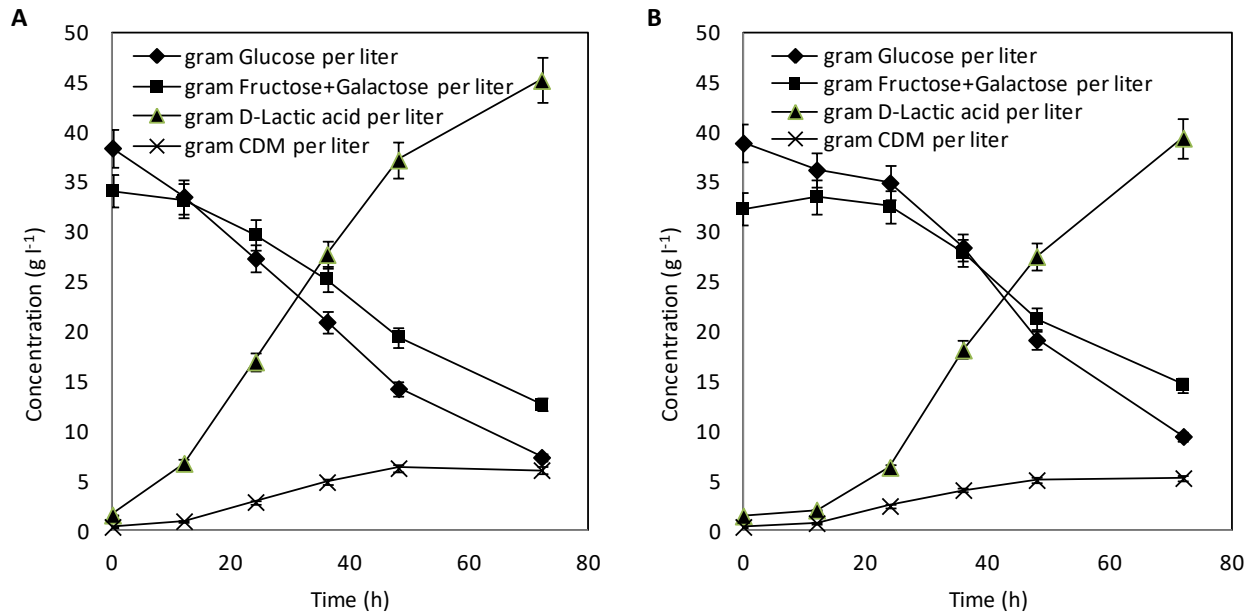

Figure 5. Growth, sugar consumption and D-LA production from OPW hydrolysate in bioreactor and batch mode. A. Lactobacillus delbrueckii ssp. delbreckii CECT 286. B. Lactobacillus delbrueckii ssp. bulgaricus CECT 5037. CDM = Cell dry weight. 
The yields obtained were similar to those obtained in previous assays by adjusting $\mathrm{pH}$, but the productivities were higher in this case, with values of 0.63 and $0.55 \mathrm{~g} \mathrm{~L}^{-1} \mathrm{~h}^{-1}$, respectively. The experiments show that sugars are not completely consumed during fermentation, probably due to deficiencies in the nutritional requirements of the strains. Therefore, the D-LA production process is further optimizable using L. delbrueckii ssp. bulgaricus CECT 5037 as a promising D-LA producer from OPW hyrolysate and other sustainable feedstocks to contribute in the development of bio-waste refineries. In this regard, commercially important LA-producing LAB strains, such as Lactobacillus and Sporolactobacillus strains, are particularly useful because of their high lactic acid yield, high acid tolerance, and their ability to be metabolically engineered $[9,12]$. Efficient conversion of biomass to D-LA still faces considerable challenges, such as high energy demand and high enzyme cost for pretreatment of lignocellulosic biomass, inefficiency of sugar utilization by microorganisms, and undesired byproducts generated during the fermentation process [46]. Table 3 summarizes studies of D-LA production from sustainlable feedstocks such as agro-industrial residues by wild-type stains. These results indicate that OPW hydrolysate is an interesting feedstock for the production of D-LA, since the product yield is close to its theoretical value $\left(\mathrm{g} \mathrm{g}^{-1}\right)$ in most cases. Apart from that, the productivity value is quite high and very attractive when industrial developments are envisaged [32,48]. It is common that bioprocesses based on biomass waste give poorer results than their control experiments based on sugar mixtures resembling the hydrolysates composition. In this case, yields achieved have close values in both cases. According to the achieved purity of lactic acid ( $>95 \%)$, differences were not observed when OPW hydrolysate is used, suggesting that the waste compounds do not influence D-LA purity.

Table 3. D-LA production from sustainable feedstocks in batch cultures by wild-type LAB strains.

\begin{tabular}{|c|c|c|c|c|c|c|}
\hline Feedstock & Microorganism & Process & $\begin{array}{l}\text { Yield } \\
\left(\mathrm{g} \mathrm{g}^{-1}\right)\end{array}$ & $\begin{array}{l}\text { Productivity } \\
\left(\mathrm{g} \mathrm{L}^{-1} \mathrm{~h}^{-1}\right)\end{array}$ & $\begin{array}{c}\text { D-LA } \\
(\%)\end{array}$ & Reference \\
\hline Rice starch & L. delbrueckii LD 0028 & SHF & 0.70 & 1.55 & 97.5 & [49] \\
\hline Defatted rice bran & L. delbrueckii IFO 3202 & SSF & 0.78 & 1.25 & $>95$ & [10] \\
\hline Sugarcane molasses & L. delbrueckii JCM 1148 & - & 0.90 & 1.48 & 97.2 & [31] \\
\hline Sugarcane juice & L. delbrueckii JCM 1148 & - & 0.95 & 1.66 & 98.3 & [31] \\
\hline Sugar beet juice & L. delbrueckii JCM 1148 & - & 0.88 & 1.16 & 97.6 & {$[31]$} \\
\hline Microalga & L. coryniformis ssp. torquens ATCC 25600 & SSF & 0.46 & 1.02 & 95.8 & {$[50]$} \\
\hline Curcuma longa waste & L. coryniformis ssp. torquens ATCC 25600 & SSF & 0.65 & 2.08 & $>95$ & [51] \\
\hline Pulp & L. delbrueckii ATCC 9649 & SHF & 0.83 & 1.01 & 99 & [9] \\
\hline Casein whey permeate & L. delbrueckii ssp. lactis ATCC 4797 & - & 0.49 & 0.61 & $>98$ & [52] \\
\hline Pulp mill residues & L. coryniformes ssp. torquens ATCC 25600 & SHF & 0.97 & 2.80 & 99 & [53] \\
\hline Orange peel waste & L. delbrueckii ssp. delbrueckii CECT 286 & SHF & 0.88 & 2.35 & $>95$ & [32] \\
\hline Orange peel waste & L. delbrueckii ssp. delbrueckii CECT 286 & SHF & 0.86 & 0.63 & 99.5 & This study \\
\hline Orange peel waste & L. delbrueckii ssp. bulgaricus CECT 5037 & SHF & 0.84 & 0.55 & 99.3 & This study * \\
\hline
\end{tabular}

* Preliminary results of LAB screening for further optimization. SSF: Simultaneous saccharification and fermentation; SHF: Separate hydrolysis and fermentation.

The results obtained with the L. delbrueckii ssp. bulgaricus CECT 5037 strain are promising since performance of the strain was comparable to L. delbrueckki ssp. delbrueckii CECT 286 strain performance using OPW hydrolysate at the conditions tested in this work. Previous studies show that the reference strain can reach a productivity of $2.35 \mathrm{~g} \mathrm{~L}^{-1} \mathrm{~h}^{-1}$ when fermentation conditions are optimized [32]. Therefore, future work with L. delbrueckii ssp. bulgaricus CECT 5037 will be focused on optimization of fermentation methodology, including the method of inoculation of the cultures, improvement of culture media by testing low cost nutrient sources, as well as the evaluation of operational costs in developing a sustainable lactic acid production process.

\section{Conclusions}

Six strains of the species Lactobacillus delbrueckii ssp. bulgaricus were evaluated for the production of D-LA from OPW hydrolysate in comparison to the reference Lactobacillus delbrueckii ssp. delbrueckii CECT 286 strain. Remarkably, Lactobacillus delbrueckii ssp. bulgaricus CECT 5037 is able to tolerate the OPW hydrolysate and produce D-LA up to $95 \%$ (e.e.). The results of strain performance show 
a yield of $84 \% w / w$ for lactic acid production that is close to the yield of $86 \% w / w$ obtained with the reference Lactobacillus delbrueckii ssp. delbrueckii CECT 286 strain in this work and $88 \%$ w/w reported from previous works when process improvement was foreseen. Experiments will be underway to develop the process and further optimization will contribute to providing a suitable alternative to biowaste-refinery processes using OPW and other residual feedstocks as a potential substrate for valorisation.

Author Contributions: D.R. and M.T. conceived the research; A.R. and D.B. designed the experiments; D.B. performed the experiments; A.R. evaluated the results; D.B. wrote the paper. All authors have read and agreed to the published version of the manuscript.

Funding: This research was funded by European Commission, grant number EIB.12.007

Conflicts of Interest: The authors declare no conflict of interest. The funders had no role in the design of the study; in the collection, analyses, or interpretation of data; in the writing of the manuscript, or in the decision to publish the results.

\section{References}

1. Esteban, J.; Ladero, M. Food waste as a source of value-added chemicals and materials: A biorefinery perspective. Int. J. Food. Sci. Technol. 2018, 53, 1095-1108. [CrossRef]

2. John, R.P.; Anisha, G.; Nampoothiri, K.M.; Pandey, A. Direct lactic acid fermentation: Focus on simultaneous saccharification and lactic acid production. Biotechnol. Adv. 2009, 27, 145-152. [CrossRef]

3. Abdel-Rahman, M.A.; Tashiro, Y.; Sonomoto, K. Lactic acid production from lignocellulose-derived sugars using lactic acid bacteria: Overview and limits. J. Biotechnol. 2011, 156, 286-301. [CrossRef]

4. Klotz, S.; Kaufmann, N.; Kuenz, A.; Prüße, U. Biotechnological production of enantiomerically pure D-lactic acid. Appl. Microbiol. Biotechnol. 2016, 100, 9423-9437. [CrossRef]

5. Wang, Y.; Tashiro, Y.; Sonomoto, K. Fermentative production of lactic acid from renewable materials: Recent achievements, prospects, and limits. J. Biosci. Bioeng. 2015, 119, 10-18. [CrossRef]

6. Singhvi, M.; Zendo, T.; Sonomoto, K. Free lactic acid production under acidic conditions by lactic acid bacteria strains: Challenges and future prospects. Appl. Microbiol. Biotechnol. 2018, 102, 1-14. [CrossRef]

7. John, R.P.; Nampoothiri, K.M.; Pandey, A. Fermentative production of lactic acid from biomass: An overview on process developments and future perspectives. Appl. Microbiol. Biotechnol. 2007, 74, 524-534. [CrossRef]

8. Tashiro, Y.; Kaneko, W.; Sun, Y.; Shibata, K.; Inokuma, K.; Zendo, T.; Sonomoto, K. Continuous D-lactic acid production by a novel thermo tolerant Lactobacillus delbrueckii subsp. lactis QU 41. Appl. Microbiol. Biotechnol. 2011, 89, 1741-1750. [CrossRef]

9. Zhang, Y.; Vadlani, P.V. D-Lactic acid biosynthesis from biomass derived sugars via Lactobacillus delbrueckii fermentation. Bioprocess Biosyst. Eng. 2013, 36, 1897-1904. [CrossRef]

10. Tanaka, T.; Hoshina, M.; Tanabe, S.; Sakai, K.; Ohtsubo, S.; Taniguchi, M. Production of D-lactid acid from defatted rice bran by simultaneous saccarification and fermentation. Bioresour. Technol. 2006, 97, 211-217. [CrossRef]

11. Abdel-Rahman, M.A.; Tashiro, Y.; Sonomoto, K. Recent advances in lactic acid production by microbial fermentation processes. Biotechnol. Adv. 2013, 31, 877-902. [CrossRef]

12. Zhang, Y.; Vadlani, P.V.; Kumar, A.; Hardwidge, P.R.; Govind, R.; Tanaka, T.; Kondo, A. Enhanced D-lactic acid production from renewable resources using engineered Lactobacillus plantarum. Appl. Microbiol. Biotechnol. 2016, 100, 279-288. [CrossRef]

13. Idris, A.; Suzana, W. Effect of sodium alginate concentration, bead diameter, initial $\mathrm{pH}$ and temperature on lactic acid production from pineapple waste using immobilized Lactobacillus delbrueckii. Process. Biochem. 2006, 41, 1117-1123. [CrossRef]

14. Choi, M.; Al-Zahrani, S.M.; Lee, S.Y. Kinetic model-based feed-forward controlled fed-batch fermentation of Lactobacillus rhamnosus for the production of lactic acid from Arabic date juice. Bioprocess Biosyst. Eng. 2014, 37, 1007-1015. [CrossRef]

15. Hu, J.; Zhang, Z.; Lin, Y.; Zhao, S.; Mei, Y.; Liang, Y.; Peng, N. High-titer lactic acid production from $\mathrm{NaOH}$-pretreated corn stover by Bacillus coagulans LA204 using fed-batch simultaneous saccharification and fermentation under non-sterile condition. Bioresour. Technol. 2015, 182, 251-257. [CrossRef] 
16. Hama, S.; Mizuno, S.; Kihara, M.; Tanaka, T.; Ogino, C.; Noda, H.; Kondo, A. Production of D-lactic acid from hard wood pulp by mechanical milling followed by simultaneous saccharification and fermentation using metabolically engineered Lactobacillus plantarum. Bioresour. Technol. 2015, 187, 167-172. [CrossRef]

17. Okano, K.; Hama, S.; Kihara, M.; Noda, H.; Tanaka, T.; Kondo, A. Production of optically pure D-lactic acid from brown rice using metabolically engineered Lactobacillus plantarum. Appl Microbiol. Biotechnol. 2017, 101, 1869-1875.

18. Van Dyk, J.S.; Gama, R.; Morrison, D.; Swart, S.; Pletschke, B.I. Food processing waste: Problems, current management and prospects for utilisation of the lignocellulose component through enzyme synergistic degradation. Renew. Sust. Energ. Rev. 2013, 26, 521-531. [CrossRef]

19. Girotto, F.; Alibardi, L.; Cossu, R. Food waste generation and industrial uses: A review. Waste. Manag. 2015, 45, 32-41. [CrossRef]

20. Rezzadori, K.; Benedetti, S.; Amante, E.R. Proposals for the residues recovery: Orange waste as raw material for new products. Food Bioprod. Process. 2012, 90, 606-614. [CrossRef]

21. Negro, V.; Mancini, G.; Ruggeri, B.; Fino, D. Citrus waste as feedstock for bio-based products recovery: Review on limonene case study and energy valorization. Bioresour. Technol. 2016, 214, 806-815. [CrossRef]

22. De la Torre, I.; Ravelo, M.; Segarra, S.; Tortajada, M.; Santos, V.E.; Ladero, M. Study on the effects of several operational variables on the enzymatic batch saccharification of orange solid waste. Bioresour. Technol. 2017, 245, 906-915. [CrossRef]

23. Choi, I.S.; Lee, Y.G.; Khanal, S.K.; Park, B.J.; Bae, H.-J. A low-energy, cost-effective approach to fruit and citrus peel waste processing for bioethanol production. Appl. Energy 2015, 140, 65-74. [CrossRef]

24. Rafiq, S.; Kaul, R.; Sofi, S.A.; Bashir, N.; Nazir, F.; Ahmad Nayik, G. Citrus peel as a source of functional ingredient: A review. J. Saudi Soc. Agric. Sci. 2016, 17, 351-358. [CrossRef]

25. Martín, M.A.; Siles, J.A.; Chica, A.F.; Martín, A. Biomethanization of orange peel waste. Bioresour. Technol. 2010, 101, 8993-8999. [CrossRef]

26. Pourbafrani, M.; Forgács, G.; Horváth, I.S.; Niklasson, C.; Taherzadeh, M.J. Production of biofuels, limonene and pectin from citrus wastes. Bioresour. Technol. 2010, 101, 4246-4250. [CrossRef]

27. Oberoi, H.S.; Vadlani, P.V.; Madl, R.L.; Saida, L.; Abeykoon, J.P. Ethanol production from orange peels: Two-stage hydrolysis and fermentation studies using optimized parameters through experimental design. J. Agric. Food Chem. 2010, 58, 3422-3429. [CrossRef]

28. Lugo-Lugo, V.; Barrera-Díaz, C.; Ureña-Núñez, F.; Bilyeu, B.; Linares-Hernández, I. Biosorption of Cr(III) and Fe(III) in single and binary systems onto pretreated orange peel. J. Environ. Manag. 2012, 112, 120-127. [CrossRef]

29. Mazzoli, R.; Bosco, F.; Mizrahi, I.; Bayer, E.A.; Pessione, E. Towards lactic acid bacteria-based biorefineries. Biotechnol. Adv. 2014, 32, 1216-1236. [CrossRef]

30. Eiteman, M.A.; Ramalingam, S. Microbial production of lactic acid. Biotechnol. Lett. 2015, 37, 955-972. [CrossRef]

31. Calabia, B.P.; Tokiwa, Y. Production of D-lactic acid from sugar cane molasses, sugarcane juice and sugar beet juice by Lactobacillus delbrueckii. Biotechnol. Lett. 2007, 29, 1329-1332. [CrossRef]

32. De la Torre, I.; Ladero, M.; Santos, V.E. Production of D-lactic acid by Lactobacillus delbrueckii ssp. delbrueckii from orange peel waste: Techno-economical assesment of nitrogen sources. Appl. Microbiol. Biotechnol. 2018, 102, 10511-10521.

33. Benthin, S.; Villadsen, J. Production of optically pure D-lactate by Lactobacillus bulgaricus and purification by crystallisation and liquid/liquid extraction. Appl. Microbiol. Biotechnol. 1995, 42, 826-829. [CrossRef]

34. Benthin, S.; Villadsen, J. Different inhibition of Lactobacillus delbrueckii subsp. bulgaricus by D- and L-lactic acid: Effects on lag phase, growth rate and cell yield. J. Appl. Biotecnol. 1995, 78, 647-654.

35. Adamberg, K.; Kaska, S.; Lahta, T.M.; Paalmea, T. The effect of temperature and $\mathrm{pH}$ on the growth of lactic acid bacteria: A pH-auxostat study. Int. J. Food. Microbiol. 2003, 85, 171-183. [CrossRef]

36. Aghababaie, M.; Beheshti, M.; Khanahmadi, M. Effect of temperature and $\mathrm{pH}$ on formulating the kinetic growth parameters and lactic acid production of Lactobacillus bulgaricus. Nutr. Food. Sci. Res. 2014, 1, 49-56.

37. Bernard, N.; Ferain, T.; Garmyn, D.; Hols, P.; Delcour, J. Cloning of the D-lactate dehydrogenase gene from Lactobacillus delbrueckii subsp. bulgaricus by complementation in Escherichia coli. FEBS Lett. 1991, 290, 61-64. [CrossRef] 
38. Hofvendahl, K.; Hahn-Hägerdal, B. Factors affecting the fermentative lactic acid production from renewable resources. Enzyme Microb. Technol. 2000, 26, 87-107. [CrossRef]

39. Sluiter, A.; Ruiz, R.; Scarlata, C.; Sluiter, J.; Templeton, D. Determination of Extractives in Biomass; Laboratory Analytical Procedure (LAP); Sluiter, A., Ed.; National Renewable Energy Laboratory: Golden, CO, USA, 2008.

40. Sluiter, A.; Hames, B.; Ruiz, R.; Scarlata, C.; Sluiter, J.; Templeton, D. Determination of Sugars, Byproducts, and Degradation Products in Liquid Fraction Process Samples; Laboratory Analytical Procedure (LAP); Sluiter, A., Ed.; National Renewable Energy Laboratory: Golden, CO, USA, 2008.

41. Sluiter, A.; Hames, B.; Ruiz, R.; Scarlata, C.; Sluiter, J.; Templeton, D.; Crocker, D. Determination of Structural Carbohydrates and Lignin in Biomass; Laboratory Analytical Procedure (LAP); Sluiter, A., Ed.; National Renewable Energy Laboratory: Golden, CO, USA, 2012.

42. Archibald, F.S.; Fridovich, I. Manganese and defenses against oxygen toxicity in Lactobacillus plantarum. J. Bacteriol. 1981, 145, 442-451.

43. Bevilacqua, A.; Corbo, M.R.; Sinigaglia, M. In vitro evaluationof the antimicrobial activity of eugenol, limonene, and citrus extract against bacteriaand yeasts, representativeofthe spoilingmicroflora of fruit juices. J. Food Prot. 2010, 73, 888-894. [CrossRef]

44. Grobben, G.J.; Chin-Joe, I.; Kitzen, V.A.; Boels, I.C.; Boer, F.; Sikkema, J.; Smith, M.R.; De Bont, J.A.M. Enhancement of exopolysaccharide production by Lactobacillus delbrueckii subsp. bulgaricus NCFB 2772 with a simplified defined medium. Appl. Environ. Microbiol. 1998, 64, 1333-1337.

45. Chervaux, C.; Ehrlich, S.D.; Maguin, E. Physiological Study of Lactobacillus delbrueckii subsp. bulgaricus Strains in a Novel Chemically Defined Medium. Appl. Environ. Microbiol. 2000, 66, 5306-5311.

46. Zhang, Y.; Yoshida, M.; Vadlani, P.V. Biosynthesis of D-lactic acid from lignocellulosic biomass. Biotechnol. Lett. 2018, 40, 1167-1179. [CrossRef]

47. Kwon, S.; Lee, P.C.; Lee, E.G.; Chang, Y.K.; Chang, N. Production of lactic acid by Lactobacillus rhamnosus with vitamin-supplemented soybean hydrolysate. Enzym. Microb. Technol. 2000, 26, 209-215. [CrossRef]

48. De la Torre, I.; Acedos, M.G.; Ladero, M.; Santos, V.E. On the use of resting L. delbrueckii spp. delbrueckii cells for D-lactic acid production from orange peel wastes hydrolysates. Biochem. Eng. J. 2019, 145, 162-169.

49. Fukushima, K.; Sogo, K.; Miura, S.; Kimura, Y. Production of D-lactic acid by bacterial fermentation of rice starch. Macromol. Biosci. 2004, 4, 1021-1027. [CrossRef]

50. Nguyen, C.M.; Kim, J.S.; Song, J.K.; Choi, G.J.; Choi, Y.H.; Jang, K.S.; Kim, J.C. D-lactic acid production from dry biomass of Hydrodictyon reticulatum by simultaneous saccharification and co-fermentation using Lactobacillus coryniformis subsp torquens. Biotechnol. Lett. 2012, 34, 2235-2240. [CrossRef]

51. Nguyen, C.M.; Kim, J.S.; Nguyen, T.N.; Kim, S.K.; Choi, G.J.; Choi, Y.H.; Jang, K.S.; Kim, J.C. Production of L- and D-lactic acid from waste Curcuma longa biomass through simultaneous saccharification and cofermentation. Bioresour. Technol. 2013, 146, 35-43. [CrossRef]

52. Prasad, S.; Srikanth, K.; Limaye, A.M.; Sivaprakasam, S. Homo-fermentative production of d-lactic acid by Lactobacillus sp. employing casein whey permeate as a raw feed-stock. Biotechnol. Lett. 2014, 36, 1303-1307. [CrossRef]

53. De Oliveira Moraes, A.; Ramirez, N.I.B.; Pereira, N. Evaluation of the fermentation potential of pulp mill residue to produce $\mathrm{D}(-)$-lactic acid by separate hydrolysis and fermentation using Lactobacillus coryniformis subsp. torquens. Appl. Biochem. Biotechnol. 2016, 180, 1574-1585. [CrossRef]

(C) 2019 by the authors. Licensee MDPI, Basel, Switzerland. This article is an open access article distributed under the terms and conditions of the Creative Commons Attribution (CC BY) license (http://creativecommons.org/licenses/by/4.0/). 